\title{
Nanostructural Formation of Pd-Co Bimetallic Complex on HOPG Surfaces: XPS and AFM Studies
}

\author{
Lisandra Arroyo-Ramírez, Rubenier Montano-Serrano, Raphael G. Raptis, \\ and Carlos R. Cabrera
}

Department of Chemistry and Center for Advanced Nanoscale Materials, Institute for Functional Nanomaterials, University of Puerto Rico, Río Piedras Campus, P.O. Box 23346, San Juan, PR 00931-3346, USA

Correspondence should be addressed to Carlos R. Cabrera, ccabrera@uprrp.edu

Received 18 October 2008; Accepted 28 January 2009

Recommended by John S. Foord

\begin{abstract}
A new single source approach was developed to synthesize Pd-Co nanoparticles using a bimetallic compound, $\left[\mathrm{Et}_{3} \mathrm{NH}\right]_{2}\left[\mathrm{CoPd}_{2}\left(\mu-4-\mathrm{I}-3,5-\mathrm{Me}_{2} \mathrm{pz}_{4} \mathrm{Cl}_{4}\right]\left(\mathrm{CoPd}_{2}\right)\right.$, as a molecular precursor to obtain dispersed catalyst on highly ordered pyrolytic graphite (HOPG) surface, in view of preparing oxygen reduction catalysts for low temperature fuel cells. Xray photoelectron spectroscopy (XPS) and atomic force microscopy (AFM) techniques were employed to characterize the nanostructure formations and to determine the composition and morphology of the complex on the HOPG. Results of high resolution XPS analysis (HR-XPS) revealed the binding energies corresponding to the atomic constituents of the precursor. When the precursor solution was placed on the surface of the HOPG, the bimetallic complex assumes a tubular structure and it appears that the surface of the HOPG offers a ground for the self-organization of nanostructural formations.
\end{abstract}

Copyright () 2009 Lisandra Arroyo-Ramírez et al. This is an open access article distributed under the Creative Commons Attribution License, which permits unrestricted use, distribution, and reproduction in any medium, provided the original work is properly cited.

\section{Introduction}

Nanoarchitecture is an emerging area that fuels the interests of scientists and engineers alike, largely due to the novel material properties that can be engineered and tuned at molecular levels. These nanomaterials are mainly used for heterogeneous catalysis. Platinum is used extensively as a catalyst in both anodes and cathodes of low-temperature polymer electrolyte fuel cells. Low-temperature fuel cells are considered alternate power sources for portable and transportation applications [1]. In spite of its excellent electrocatalytic activity, the use of monometallic platinum is disadvantageous due to its intermediate poisoning and high cost. Sophisticated bimetallic, cost-effective Pd-Co catalysts were recently proposed for oxygen reduction reaction in lowtemperature fuel cells, especially for direct methanol fuel cell applications due to their methanol tolerance ability and appreciable oxygen reduction efficiency [2].

When bimetallic catalysts are prepared by using multiple precursors, it is difficult to attain homogeneous catalytic system characterized by a uniform particles size distribution.
In order to achieve such objective, in this paper, a single organometallic precursor characterized by a well-defined PdCo ratio has been used. This approach would allow the formation of nanostructures and nanoparticles with defined size and composition distribution.

This paper reports on the characterization of a $\mathrm{CoPd}_{2}$ precursor and deposition for the nanoarchitectural formation on highly ordered pyrolytic graphite surface through surfaces analysis techniques such as $\mathrm{X}$-ray photoelectron spectroscopy (XPS) and atomic force microscopy (AFM).

\section{Experimental}

The ionic precursor of $\left[\mathrm{Et}_{3} \mathrm{NH}\right]_{2} \quad\left[\mathrm{CoPd}_{2}(\mu-4-\mathrm{I}-3,5-\right.$ $\left.\mathrm{Me}_{2} \mathrm{pz}_{4} \mathrm{Cl}_{4}\right]\left(\mathrm{CoPd}_{2}\right)$ was synthesized following the procedure from [3]. An exfoliated piece of highly ordered pyrolytic graphite (HOPG) spi-2 grade was used as the substrate. Approximately $100 \mu \mathrm{L}$ of $\mathrm{CoPd}_{2}$ precursor $(0.5 \mathrm{mM})$ in dichloromethane solution was deposited on HOPG surface and allowed to dry. This sample was placed under vacuum for one hour and analyzed by surface 


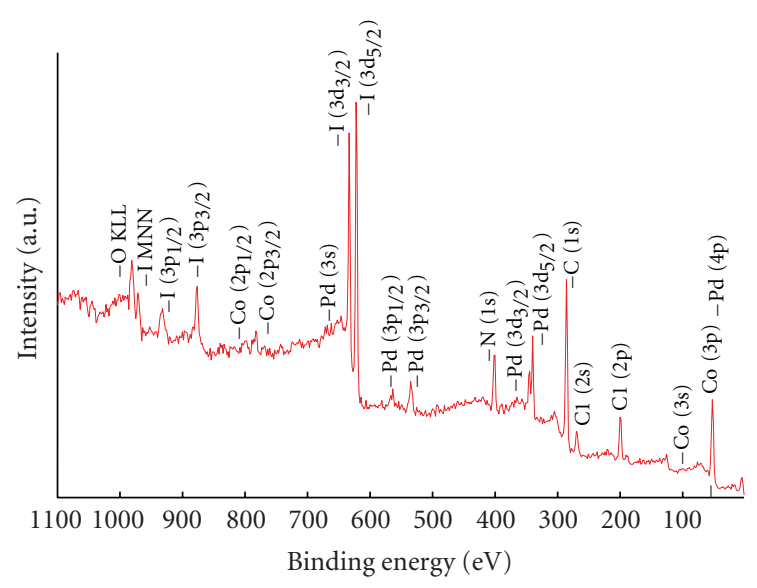

FIgURE 1: XPS survey spectra of the $\operatorname{CoPd}_{2}$ precursor.

analytical techniques. The reduction process was performed in a closed tube furnace by increasing the temperature to over $600^{\circ} \mathrm{C}$ under an $\mathrm{H}_{2}$ stream. The samples were cool-off in an $\mathrm{H}_{2}$ atmosphere to $\sim 63^{\circ} \mathrm{C}$ and they were purged with $\mathrm{N}_{2}$ until they reached room temperature before opening the stainless steel system.

Our scanning probe microscope was a Nanoscope IIIaMultimode atomic force microscope (AFM) from Digital Instruments, with a scanning probe microscope controller equipped with $\mathrm{He}-\mathrm{Ne}$ laser $(638.2 \mathrm{~nm})$ and scanner type E. A standard $\mathrm{Si}_{3} \mathrm{~N}_{4}$ cantilever was used for contact mode imaging, and the scan rate was $1 \mathrm{~Hz}$.

X-ray photoelectron spectroscopy (XPS) was used to determine the composition of the precursors. A PHI 5600ci spectrometer with an $\mathrm{Al} \mathrm{K} \alpha$ monochromatic $\mathrm{X}$-ray source at $15 \mathrm{kV}$ and $350.0 \mathrm{~W}$ was used to obtain a survey and multiplex XPS spectra. Spectrum was recorded at a take-off angle of $45^{\circ}$ and pass energy of $187.8 \mathrm{eV}$ for the survey and $58.7 \mathrm{eV}$ for the high-energy resolution studies. The binding energies were corrected using the carbon $(\mathrm{C} 1 \mathrm{~s})$ contamination peak at $284.5 \mathrm{eV}$.

\section{Results and Discussion}

Surface analytical techniques were employed to study the nanoarchitectural formation of a new heterobimetallic compound on the surface of HOPG. The molecular complex had $\mathrm{Pd}(\mathrm{II})$ and $\mathrm{Co}(\mathrm{II})$ metals with chloride and dimethyliodopyrazolate ligands. The chemical composition of the $\left[\mathrm{Et}_{3} \mathrm{NH}\right]_{2}$ $\left[\mathrm{CoPd}_{2}\left(\mu-4-\mathrm{I}-3,5-\mathrm{Me}_{2} \mathrm{pz}\right)_{4} \mathrm{Cl}_{4}\right]\left(\mathrm{CoPd}_{2}\right)$ complex and the modified HOPG surface were determined by XPS analysis. The XPS survey spectrum for the $\mathrm{CoPd}_{2}$ precursor showed the peaks attributed to $\mathrm{C}, \mathrm{N}, \mathrm{I}, \mathrm{Cl}, \mathrm{Pd}$, and Co atoms (see Figure 1).

The high-resolution XPS (HR-XPS) was used to identify the metals present in the precursor. The observed HR-XPS binding energy (BE) peaks are summarized in Table 1.

Figure 2 shows the high-resolution XPS spectrum corresponding to palladium (3d) and cobalt (2p) binding energy regions for the $\mathrm{CoPd}_{2}$ precursor. In the $\mathrm{Pd} 3 \mathrm{~d}_{5 / 2}$ region,

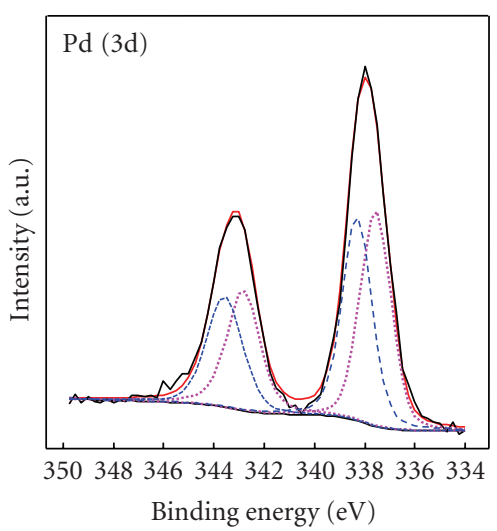

(a)

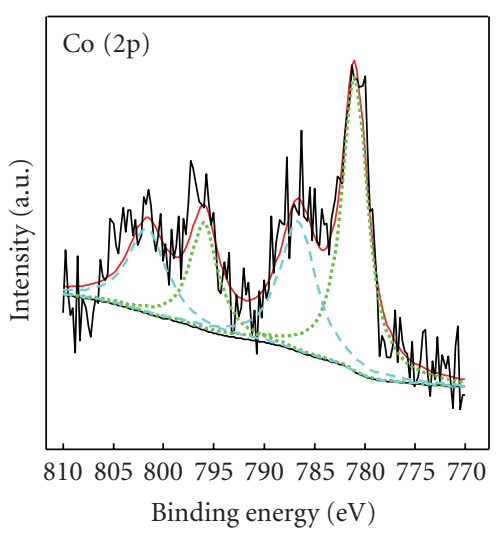

(b)

FIgURE 2: HR-XPS spectra corresponding to Pd $3 \mathrm{~d}$ and Co $2 \mathrm{p}$ binding energy regions of the $\mathrm{CoPd}_{2}$ precursor.

the HR-XPS spectrum shows two peaks with binding energy values of 337.9 and $339.5 \mathrm{eV}$ for the $\mathrm{Pd}-\mathrm{Cl}$ and $\mathrm{Pd}-\mathrm{N}$, respectively. These values are in agreement with the binding energy values of 337.8 and $337.9 \mathrm{eV}$ for $\mathrm{PdCl}_{2}$ and $339.0 \mathrm{eV}$ for $\mathrm{K}_{2} \mathrm{Pd}\left(\mathrm{NO}_{2}\right)_{4}$ compounds $[4,5]$.

In the Co region, the peak with $\mathrm{BE}$ of $781.3 \mathrm{eV}$ is attributed to cobalt at precursor and a shakeup satellite peak at $787.0 \mathrm{eV}[6]$. The binding energy values for Co $2 \mathrm{p}_{3 / 2}$, in the precursor, were similar to those reported in literature for other cobalt compounds with $\mathrm{Cl}-\mathrm{Co}-\mathrm{N}$ bonds [4]. The other binding energy values were as follows: I in 4-I-pz, $661.9 \mathrm{eV}$; and $\mathrm{Cl}$ in Cl-Co and Cl-Pd, $197.3 \mathrm{eV}$ and $198.1 \mathrm{eV}$, respectively. The binding energy obtained for nitrogen in the pyrazolate was found at different regions such as 339.1, 400.1, 401.5 , and $402.6 \mathrm{eV}$, and this has been due to the different chemical environments prevailing in the precursor. The $\mathrm{C}-$ $\mathrm{C}, \mathrm{C}-\mathrm{I}$, and $\mathrm{C}-\mathrm{N}$ bonds in the pyrazolate can be ascertained from corresponding binding energy values such as 284.5, 285.3 , and $286.1 \mathrm{eV}$, respectively.

The XPS spectrum for the unmodified HOPG surface was used as a reference. A clean HOPG survey spectrum showed only the typical $\mathrm{C}(1 \mathrm{~s})$ and $\mathrm{O}(1 \mathrm{~s})$ peaks. On the other hand, the XPS survey spectrum confirmed the modification of the HOPG surface with the complex $\mathrm{CoPd}_{2}$. Typical 
TABLE 1: Binding energy (BE) values obtained from HR-XPS studies for the free standing $\mathrm{CoPd}_{2}$ precursor and $\mathrm{CoPd}_{2}$ precursor on HOPG surface.

\begin{tabular}{lcc}
\hline \multirow{2}{*}{ Elements } & \multicolumn{2}{c}{ Binding energy $(\mathrm{eV})$} \\
& Free precursor & Precursor on HOPG \\
\hline $\mathrm{Pd}\left(3 \mathrm{~d}_{5 / 2}\right)$ & 337.9 & 338.4 \\
& 339.5 & 339.6 \\
$\mathrm{Co}\left(2 \mathrm{p}_{3 / 2}\right)$ & 781.3 & 781.9 \\
& 787.0 & 787.0 \\
$\mathrm{I}\left(3 \mathrm{~d}_{5 / 2}\right)$ & 621.9 & 621.3 \\
$\mathrm{Cl}(2 \mathrm{p})$ & 197.3 & 198.4 \\
& 198.1 & 199.7 \\
& 399.1 & 399.7 \\
$\mathrm{~N}(1 \mathrm{~s})$ & 400.1 & 400.6 \\
& 401.5 & 401.7 \\
& 402.6 & 402.7 \\
$\mathrm{C}(1 \mathrm{~s})$ & 284.5 & 284.5 \\
& 285.3 & 285.4 \\
\hline
\end{tabular}

element peaks for $\mathrm{Pd}(3 \mathrm{~d}), \mathrm{Co}(2 \mathrm{p}), \mathrm{I}(3 \mathrm{~d}), \mathrm{N}(1 \mathrm{~s}), \mathrm{Cl}(2 \mathrm{p})$, $\mathrm{C}(1 \mathrm{~s}), \mathrm{O}(1 \mathrm{~s})$, and $\mathrm{Si}(2 \mathrm{p})$ were present in this spectrum. This has been attributed to the adsorption of $\mathrm{CoPd}_{2}$ precursor on the HOPG surface. The Si (2p) and O (1s) impurities might have originated from the glassware used in the preparation of the sample.

It is known that the deposition is highly influenced by the substrate surface characteristics. Also, the shape and size of the deposit depends on the substrate employed. Highly ordered pyrolytic graphite is a nonpolar, highly pure carbon, with a smooth surface and basal plane featuring a few defects. The HOPG surface image was obtained using an AFM to study the morphological change which would arise as a result of the modification process. AFM images of HOPG modified with a $\mathrm{CoPd}_{2}$ precursor showed the formation of organized circular nanostructures of different sizes (Figure 3). These nanostructures on HOPG exhibited a tube-like shape in micro- to nanosize regime diameter and height. The AFM section analysis has been used for size determination of the nanostructures.

In Figure 3(a), the rings exhibit diameters which range from $156 \mathrm{~nm}$ to $2.03 \mu \mathrm{m}$ and heights between 25 and $385 \mathrm{~nm}$. Figure 3(b) shows rings with diameters ranging from $234 \mathrm{~nm}$ to $1.86 \mu \mathrm{m}$ and heights between 14 and $200 \mathrm{~nm}$. Their inner diameters span from 30 to $898 \mathrm{~nm}$ and wall thickness between 117 and $391 \mathrm{~nm}$. Some structures are volcano-like shapes with the top end of the wall smaller in diameter than the bottom.

Other samples examined by AFM and scanning electron microscopy (SEM) showed diameters ranging from $150 \mathrm{~nm}$ to $8.1 \mu \mathrm{m}$ and the heights between 10 and $400 \mathrm{~nm}$ with a maximum frequency at $60 \mathrm{~nm}$. Similar results were observed with palladium precursors $[7,8]$. The interaction between
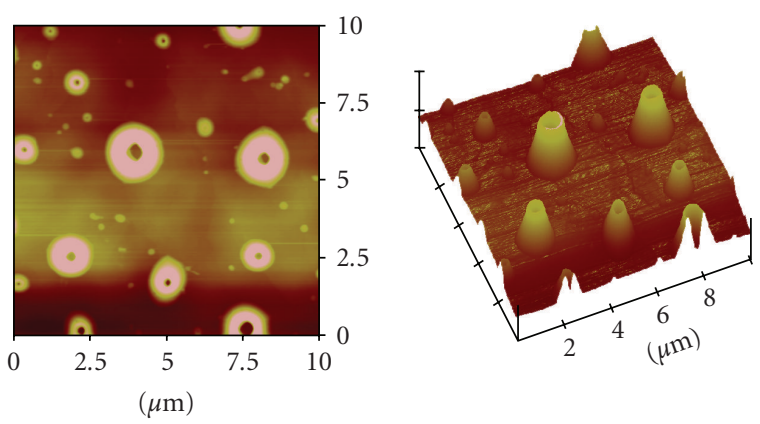

(a)
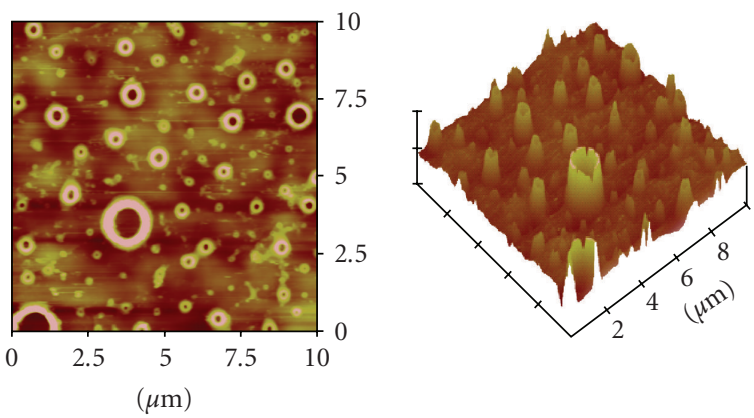

(b)

Figure 3: AFM images top and 3D view (a) $10 \mu \mathrm{m} \times 10 \mu \mathrm{m} \times$ $380 \mathrm{~nm}$ and (b) $10 \mu \mathrm{m} \times 10 \mu \mathrm{m} \times 160 \mathrm{~nm}$ for deposited of $\mathrm{CoPd}_{2}$ precursor on HOPG surfaces.

precursor-solvent-substrate and the evaporation process play an important role in the rings structure formation $[8,9]$. Gómez-Segura et al. reported the self-assembly of $\mathrm{Mn}_{12}$ microrings in the HOPG surfaces [9]. $\mathrm{CoPd}_{2}$ precursor is a nonpolar complex allowing the interaction with the HOPG surface. The organic ligands $\left(\left(\mu-4-\mathrm{I}-3,5-\mathrm{Me}_{2} \mathrm{pz}\right)_{4} \mathrm{Cl}_{4}\right)$ in the precursor prevent the random particles dispersion, and hence the solution drops evaporate to form the same type of structures. Different structural size formations can be seen when the samples are prepared in different days, perhaps due to the humidity change on a given day. It is assumed that the structural difference causes this change. Development of palladium-cobalt nanostructures with defined sizes can be controlled by the characteristics of the support surface and the environment used in the deposition process. The process of circular structure formation is not fully understood and a study with humidity control is underway.

The $\mathrm{CoPd}_{2}$ precursor was thermally reduced under hydrogen atmosphere, a procedure which removes the organic ligands. The rings formation tendency is preserved after the reduction process. This nanostructures show different size distributions on the surface. Moreover, in the images of the AFM, it is possible to observe the rings formed by bimetallic particles (see Figure 4).

In the survey spectrum after the reduction process, the corresponding peaks of pyrazolate ligands disappear while the Pd and Co peaks shift their binding energy. The $\mathrm{CoPd}_{2}$ precursor reduced has a $\mathrm{BE}$ at $335.0 \mathrm{eV}, 335.9 \mathrm{eV}$, 

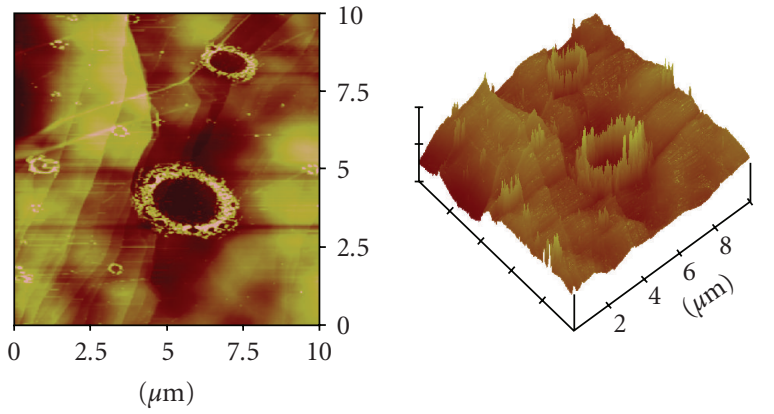

Figure 4: AFM images top and 3D view $(10 \mu \mathrm{m} \times 10 \mu \mathrm{m} \times 100 \mathrm{~nm})$ after thermal reduction of $\mathrm{CoPd}_{2}$ precursor on HOPG surface.

and $337.4 \mathrm{eV}$ for $\mathrm{Pd} 3 \mathrm{~d}_{5 / 2}$, which shows the presence of three different species. The literature reports binding energy values of $335.1 \mathrm{eV}$ for $\mathrm{Pd}$ metallic [4], $335.7 \mathrm{eV}$ for PdCo alloy $[10,11]$, and $337.9 \mathrm{eV}$ for $\mathrm{PdO}_{2}$ and $\mathrm{PdCl}_{2}[4,5,12]$. For the Co region, the peak at $781.5 \mathrm{eV}$ is higher than the cobalt metallic [5] and can be attributed to cobalt bimetallic because they are similar to reported value $(781.9 \mathrm{eV})$ at literature for PtCo bimetallic [13]. On the other hand, the BE at $787.3 \mathrm{eV}$ is for the shakeup satellite of cobalt. The binding energy shifts could be caused by the Pd-Co alloy formation. We can observe similar results with the precursor reduced on HOPG surface. For the $\mathrm{Pd} 3 \mathrm{~d}_{5 / 2}$ region, the $\mathrm{BE}$ is of $335.3 \mathrm{eV}$, $336.1 \mathrm{eV}$, and $338.1 \mathrm{eV}$. The binding energies of $781.3 \mathrm{eV}$, $783.8 \mathrm{eV}$, and $788.2 \mathrm{eV}$ correspond to Co region. Also, the binding energy displacement in the $\mathrm{Pd}$ and Co regions shows the change of oxidation state and demonstrates that the modified HOPG surface changes after the reduction process.

HOPG provides the surface for the nanostructures preparation and it can be used as an electrode for electrochemical analysis. In addition, these nanostructures with different size distribution in the HOPG surfaces may lead to its development for diverse applications.

Our future work would be focused on optimizing the conditions (e.g., relative humidity) for the nanostructures formation at HOPG surfaces. We are also studying different precursors and surfaces to see if they exhibit a similar behavior. These precursors have the same ligands but with different metal combinations like $\mathrm{Pd}-\mathrm{Ni}, \mathrm{Pd}-\mathrm{Cu}, \mathrm{Pt}-\mathrm{Co}$, among others. These combinations open the possibility of straightforward development of nanomaterials for various applications. Furthermore, the obtained novel metallic nanostructures and nanoparticles from $\mathrm{CoPd}_{2}$ precursor will be evaluated for oxygen reduction reaction in fuel cell cathode applications.

\section{Conclusion}

We prepared a promising bimetallic nanocatalyst by chemical method from single precursor. The XPS spectrum of the $\left[\mathrm{Et}_{3} \mathrm{NH}\right]_{2}\left[\mathrm{CoPd}_{2}\left(\mu-4-\mathrm{I}-3,5-\mathrm{Me}_{2} \mathrm{pz}\right)_{4} \mathrm{Cl}_{4}\right]$ precursor and modified HOPG surface confirmed the interaction between the precursor and the substrate. HR-XPS allowed the analysis of different species present in the precursor. The AFM image showed circular structures in the range of micro- to nanometer with the precursor's deposition at HOPG surface. Hence, this study is vitally important in the aspects of developing nanostructures and nanoparticles in well-defined support surfaces. This precursor is a promising new material for obtaining Pd-Co nanorings with self-formation at HOPG surfaces.

\section{Acknowledgments}

This research is supported in part by NASA Training Grant NNG05GG78H (PR Space Grant), NASA-URC Grant nos. NCC3-1034 and NNX08BA48A, NSF Grant no. 0701525, and Alliance for Graduate Education and the Professoriate (AGEP) Fellowship. The authors also thank Ramonita DíazAyala, Dr. Esteban Fachini and Dr. M. Aulice Scibioh for their helpful discussions. Moreover, they acknowledge the Materials Characterization Center (MCC) at the University of Puerto Rico at Río Piedras for the XPS analysis.

\section{References}

[1] B. Viswanathan and M. A. Scibioh, Fuel Cells: Principles and Applications, CRC Press, Boca Raton, Fla, USA, 2008.

[2] O. Savadogo, K. Lee, K. Oishi, S. Mitsushima, N. Kamiya, and K.-I. Ota, "New palladium alloys catalyst for the oxygen reduction reaction in an acid medium," Electrochemistry Communications, vol. 6, no. 2, pp. 105-109, 2004.

[3] H. N. Miras, H. Zhao, R. Herchel, C. Rinaldi, S. Pérez, and R. G. Raptis, "Synthesis and characterization of linear trinuclear $\mathrm{Pd}, \mathrm{Co}$, and Pd/Co pyrazolate complexes," European Journal of Inorganic Chemistry, vol. 2008, no. 30, pp. 4745-4755, 2008.

[4] J. F. Moulder, W. F. Stickle, P. E. Sobol, and K. D. Bomben, Handbook of X-Ray Photoelectron Spectroscopy: A Reference Book of Standard Spectra for Identification and Interpretation of XPS Data, Perkin-Elmer, Eden Prairie, Minn, USA, 1992.

[5] G. Kumar, J. R. Blackburn, R. G. Albridge, W. E. Moddeman, and M. M. Jones, "Photoelectron spectroscopy of coordination compounds-II. Palladium complexes," Inorganic Chemistry, vol. 11, no. 2, pp. 296-300, 1972.

[6] F. B. Noronha, M. Schmal, B. Moraweck, et al., "Characterization of niobia-supported palladium - cobalt catalysts," The Journal of Physical Chemistry B, vol. 104, no. 23, pp. 54785485, 2000.

[7] R. Díaz-Ayala, L. Arroyo, R. G. Raptis, and C. R. Cabrera, "Thermal reduction of $\mathrm{Pd}$ molecular cluster precursors at highly ordered pyrolytic graphite surfaces," Langmuir, vol. 20, no. 19, pp. 8329-8335, 2004.

[8] R. Díaz-Ayala, E. R. Fachini, R. G. Raptis, and C. R. Cabrera, "Palladium nanostructures and nanoparticles from molecular precursors on highly ordered pyrolytic graphite," Langmuir, vol. 22, no. 24, pp. 10185-10195, 2006.

[9] J. Gómez-Segura, O. Kazakova, J. Davies, P. Josephs-Franks, J. Veciana, and D. Ruiz-Molina, "Self-organization of $\mathrm{Mn}_{12}$ single-molecule magnets into ring structures induced by breath-figures as templates," Chemical Communications, no. 45, pp. 5615-5617, 2005.

[10] K. Lee, O. Savadogo, A. Ishihara, S. Mitsushima, N. Kamiya, and K.-I. Ota, "Methanol-tolerant oxygen reduction electrocatalysts based on Pd-3D transition metal alloys for direct methanol fuel cells," Journal of the Electrochemical Society, vol. 153, no. 1, pp. A20-A24, 2006. 
[11] L. Zhang, K. Lee, and J. Zhang, "Effect of synthetic reducing agents on morphology and ORR activity of carbon-supported nano-Pd-Co alloy electrocatalysts," Electrochimica Acta, vol. 52, no. 28, pp. 7964-7971, 2007.

[12] D. Bera, S. C. Kuiry, Z. U. Rahman, and S. Seal, “Templateassisted deposition of palladium nanoarrays preparation, microscopic, and spectroscopic studies," Journal of the Electrochemical Society, vol. 152, no. 8, pp. C566-C570, 2005.

[13] Z. Zsoldos and L. Guczi, "Structure and catalytic activity of alumina supported platinum-cobalt bimetallic catalysts. 3 . Effect of treatment on the interface layer," The Journal of Physical Chemistry, vol. 96, no. 23, pp. 9393-9400, 1992. 

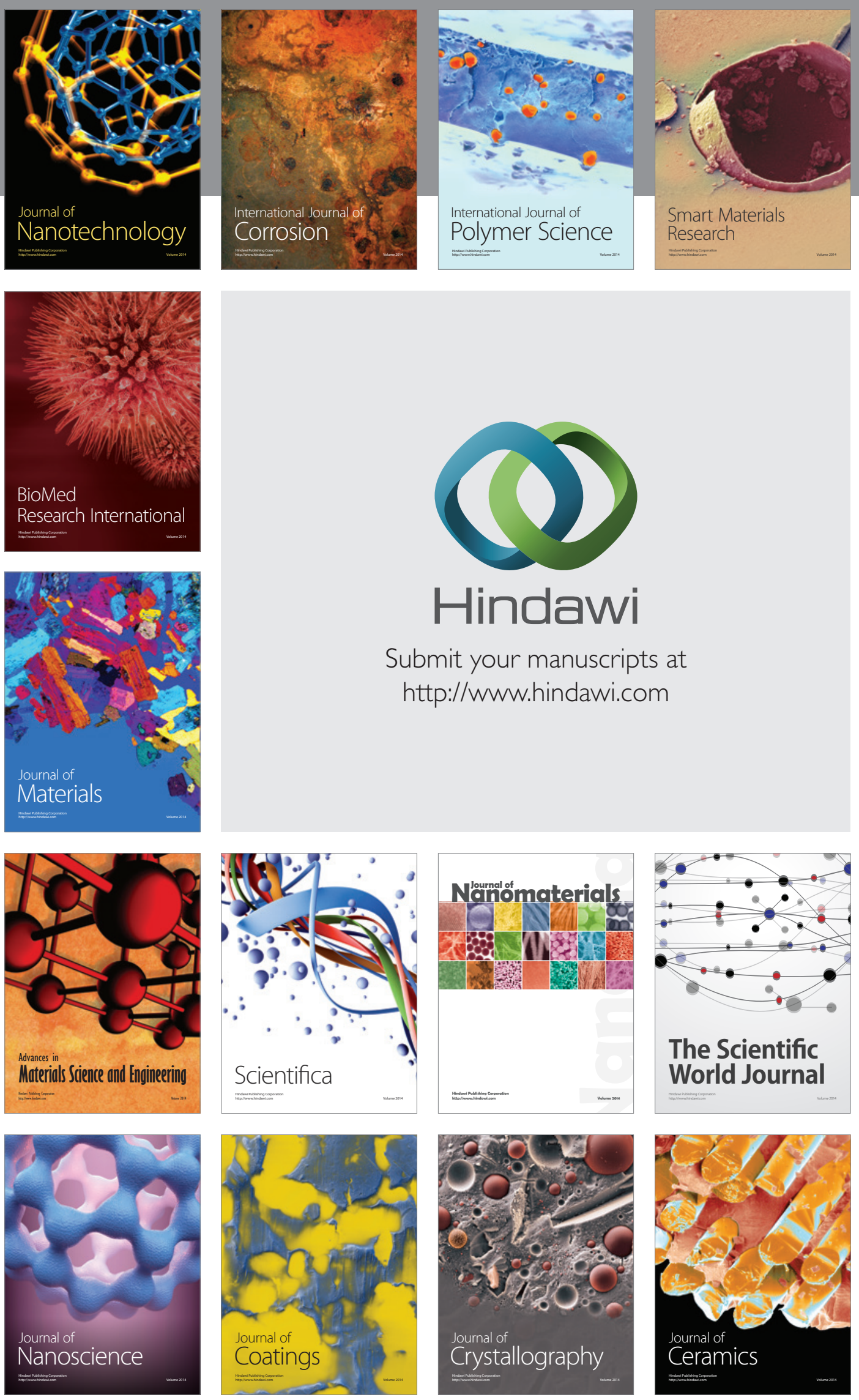

The Scientific World Journal

Submit your manuscripts at

http://www.hindawi.com

\section{World Journal}

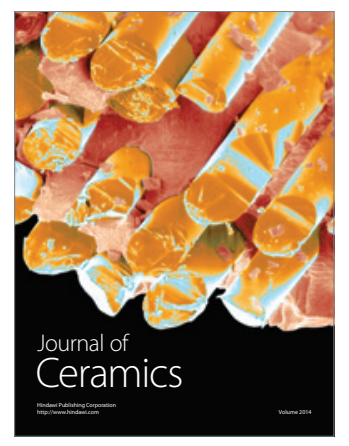

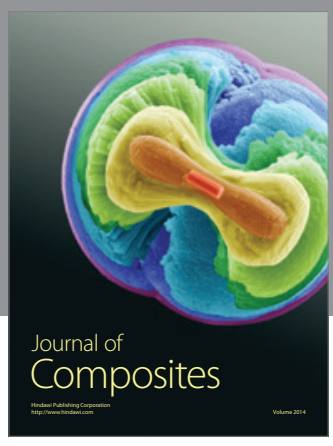
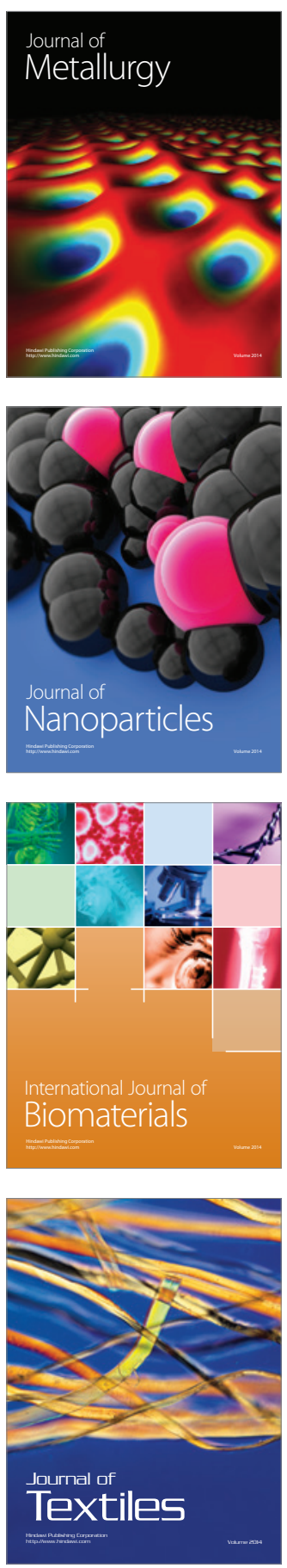